Revista Mídia e Cotidiano

ISSN: 2178-602X

Artigo Seção Livre

Volume 14, Número 2, maio-ago. de 2020

Submetido em: 18/09/2019

Aprovado em: 03/02/2020

\title{
$O$ adolescente em conflito com a lei na pauta de dois sites de Campo Grande, MS
}

\section{The issue of teenagers in conflict with the law on the agenda of two websites in Campo Grande, MS}

\author{
Taís Marina TELLAROLI ${ }^{1}$ \\ Paula Vitorino GUIMARÃES ${ }^{2}$
}

\begin{abstract}
Resumo
O objetivo desta pesquisa é analisar a presença do adolescente em conflito com a lei no noticiário dos jornais on-line Campo Grande News e Midiamax de Campo Grande, em Mato Grosso do Sul. As análises têm o alvo de averiguar quais são os crimes com envolvimento de adolescentes noticiados e se as imagens das matérias respeitam às diretrizes em relação à preservação da identidade da pessoa com menos de 18 anos. A metodologia utilizada foi a análise de conteúdo.
\end{abstract}

Palavras-chave: Adolescente. Campo Grande. Jornalismo on-line.

\begin{abstract}
This research aims to analyze the presence of adolescents in conflict with the law in the news of the online newspapers Campo Grande News and Midiamax of Campo Grande, in the state of Mato Grosso do Sul. The analysis aims to find out in which crimes teenagers are involved and whether the images in the stories follow the guidelines for protecting the identities of young persons under the age of 18. For this study, we employed content analysis as our methodology.
\end{abstract}

Keywords: Teenager. Campo Grande. Online Journalism.

\footnotetext{
${ }^{1}$ Professora do Curso de Pós-Graduação em Comunicação e Jornalismo da Universidade Federal de Mato Grosso do Sul. Doutora em Comunicação Social pela UMESP, foi membro do Projeto Competências profissionais na TV Digital brasileira - produção, interatividade e possibilidades educativas. E-mail: taistella@ hotmail.com. ORCID: 0000-0002-6234-4904.

${ }^{2}$ Mestra em Comunicação pela Universidade Federal de Mato Grosso do Sul (UFMS) e jornalista graduada pela Universidade Católica Dom Bosco (UCDB). E-mail: paulavitorinog@gmail.com. ORCID: 00000002-6760-4082.
} 
Introdução

O jornalismo tem impacto na sociedade, seja na formação de opinião ou na influência de concepções (TRAQUINA, 2005), levando informação à população sobre o que acontece de relevante no mundo e provocando discussões acerca de temas que são destaque na mídia. Em meio ao imenso fluxo de informações noticiadas diariamente, o adolescente é personagem frequente, ganhando maior espaço no noticiário - e consequentemente na pauta da sociedade - quando é retratado em contexto de violência, preferencialmente como autor de atos violentos. O levantamento ${ }^{3}$ da Agência de Notícias dos Direitos da Infância (ANDI) ${ }^{4}$, publicado em 2012, que analisou 54 jornais do país, entre 2006 e 2010, mostra que 6.832 notícias relacionadas ao universo dos adolescentes em conflito com a lei foram publicadas no período.

Em Mato Grosso do Sul, pesquisa aponta que a maioria das notícias sobre adolescentes e crianças estão relacionadas a situações de violência. Silva (2013) analisou 1.012 matérias dos jornais Correio do Estado e $O$ Estado, publicadas entre julho de 2010 e junho de 2011, e os resultados mostraram que 45,3\% das notícias se referiam a situações de violência, seja envolvendo criança e adolescente como vítimas ou autores de atos infracionais. Outro estudo regional, com o conteúdo do jornal on-line Campo Grande News (CGNews), revelou 21 matérias distribuídas entre os dias 12 e 18 de março de 2015 com a palavra "adolescente(s)". Dentre essas, 61\%, ou seja, mais da metade (13 notícias), cita o adolescente por esse ser o autor principal ou cúmplice de algum tipo de ato infracional $^{5}$ (GUIMARÃES, 2015).

Para aprofundar o estudo do tema, considerando sua relevância, este trabalho apresenta resultados da análise sobre a presença do adolescente em conflito com a lei em

\footnotetext{
3 Levantamento denominado "Como os jornais brasileiros abordam as temáticas relacionadas ao adolescente em conflito com a lei?", que faz parte da série "Direitos em Pauta: imprensa, agenda social e adolescentes em conflito com a lei”, publicada em 2012 pela ANDI (2012a).

${ }^{4}$ Há mais de 15 anos a ANDI monitora o comportamento editorial da mídia impressa brasileira no que se refere ao noticiário sobre o universo da infância e da adolescência.

${ }^{5}$ Segundo o Estatuto da Criança e do Adolescente (ECA) (art. 103), o ato infracional é a conduta da criança ou do adolescente que pode ser caracterizada como crime ou contravenção penal. Se o infrator for pessoa com mais de 18 anos, o termo adotado é crime ou delito. Os atos infracionais incluem atitudes condenáveis, de desrespeito às leis, à ordem pública, aos direitos dos cidadãos ou ao patrimônio. Só há ato infracional se existir uma hipótese legal que determine sanção ao seu ator (por exemplo, furto, homicídio etc.). Fonte: http://andi.org.br/glossario. Acesso em: 15 maio 2016.
} 


\section{míDiA

dois jornais on-line de Mato Grosso do Sul: Midiamax e Campo Grande News, no período de 30 dias, no mês de junho de 2016. A metodologia aplicada foi a análise de conteúdo, adaptada de acordo com a proposta, e a exploração dos dados foi realizada a partir de categorizações para classificar e conduzir as análises. A pesquisa final ${ }^{6}$ resultou em três categorias, sendo que neste artigo será apresentado o resultado de apenas uma, que averigua quais são os principais crimes com envolvimento de adolescentes noticiados e se as imagens das matérias preservam a identidade dos autores menores de idade.

Os resultados comprovam que o adolescente em conflito com a lei está inserido na pauta diária dos dois jornais on-line e revela que quando se trata da abordagem do indivíduo entre 12 e 18 anos o fato desse ser autor de algum tipo de infração é o principal enfoque feito pelos jornalistas. Dentre os 30 dias observados, foram encontradas 78 notícias sobre adolescentes em conflito com a lei, ou seja, uma média de 2,5 publicações por dia sobre o assunto nos dois sites.

\section{Quando o adolescente se torna pauta: a responsabilidade ética do jornalista}

A temática do presente trabalho leva a uma indagação: dentro do campo jornalístico, quais critérios noticiosos estão relacionados ao tema e que despertam o interesse dos repórteres? A resposta pode ser encontrada analisando os diferentes apontamentos teóricos sobre o que é noticiável. Há uma característica que sobressai e está presente em diversos estudos: o desvio. Ou seja, tudo aquilo que foge do comum, da rotina estabelecida pela ordem social, é um fato com grande potencial de se tornar notícia, como no caso do adolescente autor de ato infracional, que ganha destaque na pauta diária em detrimento a outros assuntos que poderiam ser publicados nos jornais. Marcos Paulo da Silva (2014) reforça um estudo realizado pelos autores Galtung e Rudge (1965) que "quanto maior o número de aspectos desviantes de um evento, maior será sua chance de ser selecionado como notícia" (SILVA, M. 2014, p. 36)

\footnotetext{
${ }^{6}$ A pesquisa completa também verificou a presença e o contexto em que o adolescente aparece diariamente nas publicações da imprensa regional através de análise de conteúdo dos jornais on-line Campo Grande News e Midiamax.
} 
Segundo Gislene Silva (2014), os critérios de noticiabilidade estão atrelados a três questões que estão, primeiro, na origem dos fatos; em segundo, nos "critérios de noticiabilidade e no tratamento dos fatos", ligados aqui a cultura organizacional da empresa e até a cultura profissional; e por último a partir de critérios de noticiabilidade na visão dos fatos. Desta forma, os valores-notícia seguem inúmeros critérios que se relacionam entre si.

\footnotetext{
Valores-notícia, as características do fato em si, em sua origem, são somente um subgrupo de fatores agindo juntamente com esse segundo conjunto de critérios de noticiabilidade, relacionados agora ao tratamento do fato. Estudar a seleção implica, inclusive, rastrear os julgamentos próprios de cada seletor, as influências organizacionais, sociais e culturais que este sofre ao fazer suas escolhas, os diversos agentes dessas escolhas postados em diferentes cargos na redação, e até mesmo a participação das fontes e do público nessas decisões (SILVA, G. 2014, p. 53).
}

A ideia de um menino ou menina, muitas vezes recém-saído da fase da infância, praticando um delito assume maior grau de desvio e incoerência com o esperado socialmente e, com isso, desperta maior interesse do público em consumir aquela notícia. Em sua rotina de busca por notícias, o jornalista, preferencialmente, escolhe os fatos que fogem do comum para serem relatados no noticiário e conquistarem a atenção do leitor (TRAQUINA, 2005). A partir desses conceitos, pode-se esclarecer por que um delito praticado por um adolescente vira notícia e, em muitos casos, tem destaque no noticiário em detrimento de um acontecimento semelhante, mas cometido por um adulto.

Silva (2013) diz que as informações sobre crianças e adolescentes que matam, roubam ou estão envolvidos em outros atos violentos chamam a atenção e mexem com as emoções do leitor. Essa questão é enfatizada em documento da Organização das Nações Unidas para a Educação, a Ciência e a Cultura (UNESCO, 2004) ao afirmar que a maioria da imprensa mostra o jovem como um problema, sendo raras as vezes em que se mostra iniciativas positivas desses por considerarem que esses assuntos não se constituem notícia.

Mas não é suficiente apenas estudar o processo de noticiabilidade que leva o adolescente em conflito a se tonar pauta. A compreensão do tema, e a consequente 


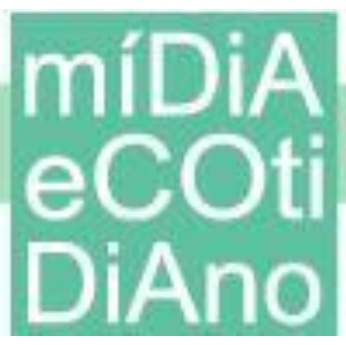

abordagem responsável, passa pelo entendimento do papel social e ético que o jornalismo exerce na sociedade, como também o conhecimento sobre as diretrizes legais que norteiam a questão e devem ser observadas pela imprensa. A cobertura jornalística tem influência nos valores construídos e discutidos pela sociedade, sendo o jornalismo tratado até como "quarto poder", conforme ressalta Nelson Traquina (2005, p. 30). Isso implica responsabilidade ainda maior na pauta elaborada diariamente e na forma como assuntos polêmicos, tal como os adolescentes em conflito com a lei, são tratados.

Os jornalistas também interagem silenciosamente com a sociedade, por via dos limites com que os valores sociais marcam as fronteiras entre normal e anormal, legítimo e ilegítimo, aceitável e desviante. As notícias têm uma estrutura profunda de valores que os jornalistas partilham, como membros da sociedade, com a sociedade (TRAQUINA, 2005, p. 29).

Considerando o impacto da mídia sobre a formação de opinião e o inegável poder que ela tem sobre os assuntos de que as pessoas irão tratar, o jornalismo tem um importante papel na responsabilidade social, de acordo com Bertrand (1999). Ainda segundo o autor, é possível destacar alguns deveres éticos do jornalista no exercício da profissão: estimular a comunicação e o entendimento entre os seres humanos (com uma linguagem desmistificada para que o leitor entenda), defender e promover os direitos do homem e da democracia, e trabalhar para melhorar a sociedade (BERTRAND, 1999).

No Código de Ética dos Jornalistas Brasileiros (FENAJ, 2007), o profissional também encontra diretrizes que devem pautar o exercício diário da profissão, como o compromisso fundamental com a verdade no relato dos fatos ${ }^{7}$. Mesmo inserido em uma empresa de comunicação, o jornalista deve estar ciente de que é responsável por toda a informação que divulga (desde que seu trabalho não tenha sido alterado por terceiros) e, por isso, cabe a ele zelar pelo cumprimento da ética no material que produz e será divulgado $^{8}$. Em relação à temática da presente pesquisa, o Código de Ética prevê, no item XI do artigo $6^{\circ}$, entre os deveres do jornalista o de "defender os direitos do cidadão, contribuindo para a promoção das garantias individuais e coletivas, em especial as das

\footnotetext{
${ }^{7}$ Retirado do artigo $4^{\text {o }}$, do Capítulo II, que trata da conduta profissional do jornalista (FENAJ, 2007).

${ }^{8}$ Retirado do artigo $8^{\circ}$, do Capítulo III, que trata da responsabilidade profissional do jornalista (FENAJ, 2007).
} 
crianças, adolescentes, mulheres, idosos, negros e minorias" (FENAJ, 2007). Transgressões às diretrizes são passíveis de punição pela Comissão Nacional de Ética, da Federação Nacional dos Jornalistas (Fenaj) ${ }^{9}$.

Há ainda um vasto campo de regras e orientações quando a questão envolve a abordagem do adolescente em conflito com a lei pela imprensa. Esse indivíduo tem seus deveres e direitos pautados por legislação própria e é primordial ao jornalista, principalmente o que atua diretamente na editoria de polícia, onde o tema é recorrente, conhecer e respeitar as normas para desempenhar adequadamente seu papel frente à sociedade. Como parte da sociedade que é, caberia a imprensa assumir de forma responsável seu papel de informar. Silva (2013) considera que o jornalismo funciona, ou pelo menos deveria, como espécie de fiscal dos instrumentos de cumprimento dos direitos dos cidadãos e justifica que a "magnitude da influência que o jornalismo exerce na vida pressupõe compromissos e deveres" (SILVA, 2013, p. 94).

O trabalho consciente da imprensa é um assunto frisado no Guia de Referência para a cobertura jornalística, "isso porque a imprensa tem a capacidade de atuar como olhos e voz independentes no acompanhamento das políticas públicas" (ANDI, 2012b, p. 59), como às direcionadas à proteção e responsabilização dos adolescentes em conflito com a lei. Para isso, um dos primeiros passos é a cobertura jornalística respeitar às diretrizes do ECA em relação à preservação da imagem da pessoa com menos de 18 anos. No artigo 143, o Estatuto veta a "divulgação de atos judiciais, policiais e administrativos que digam respeito a crianças e adolescentes a que se atribua autoria de ato infracional" (BRASIL, 2010). Na continuidade do texto, em parágrafo único, a lei esclarece que “qualquer notícia a respeito do fato não poderá identificar a criança ou o adolescente, vedando-se fotografia, referência a nome, apelido, filiação, parentesco, residência e, inclusive, iniciais do nome e sobrenome" (BRASIL, 2010). O estatuto prevê punições para o veículo de comunicação que desrespeitar as medidas (BRASIL, 2010).

Além disso, no que diz respeito à abordagem do adolescente infrator, deve-se considerar que a primeira e principal medida do sistema judiciário é a de reeducação,

\footnotetext{
${ }^{9}$ A Fenaj existe desde 1946 representa os jornalistas, em nível nacional, para defesa dos seus interesses profissionais, lutas e reivindicações. Disponível em: https://fenaj.org.br/. Acesso em: 30 out. 2016.
} 


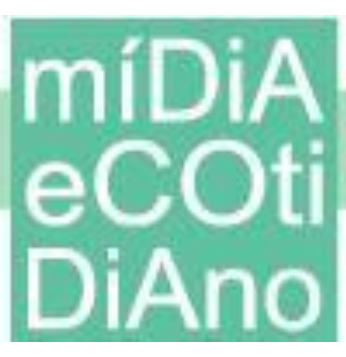

aplicada por meio de medidas socioeducativas, que vão além da finalidade do simples punir e, sim, da recuperação daquele adolescente do mundo do crime (ANDI, 2012b). Consta no ECA que as medidas socioeducativas têm caráter pedagógico e visam reinserir o infrator na sociedade e inibir a reincidência em ações consideradas inadequadas ao convívio social (BRASIL, 2010). Acioli (2012) ainda ressalta que o "espírito do ECA" não foi absorvido pela sociedade brasileira, que recebe informações de uma "mídia conservadora baseada na cultura menorista (fundamentada no Código de Menores)" (ACIOLI, 2012). A dissonância entre a realidade prevista nas políticas públicas e a cobertura realizada pela imprensa reflete, muitas vezes, em prejuízos à coletividade, com conclusões equivocadas.

\section{Adolescente em Campo Grande}

Em Campo Grande (MS), as infrações cometidas por adolescentes são encaminhadas para a Vara da Infância e da Juventude, que em dezembro de 2016 contabilizava mais de 3 mil processos em trâmite - cada um desses, em média, tem duração de cinco meses até ser concluído (KARLOH, 2016) ${ }^{10}$. Entre os atos infracionais mais frequentes na Capital, o furto tem destaque, seguido do tráfico de drogas e roubo. Os crimes que resultam em medidas de internação, geralmente, são latrocínio, homicídio, roubo e estupro, segundo explica o juiz titular da Vara da Infância e da Juventude, Mauro Nering Karloh (2016), complementando que a legislação prevê a restrição da liberdade "se o ato infracional for de violência, grave ameaça a pessoa ou na reiteração delitiva ou descumprimento de medidas anteriores" (KARLOH, 2016).

Dados do último Levantamento Anual do Sinase, feito pela Secretaria dos Direitos Humano (SDH, 2015) ${ }^{11}$ mostra que o país contava com 23.066 adolescentes e jovens (12 a 21 anos) em restrição e privação de liberdade (internação, internação provisória e semiliberdade) na data de 30 de novembro de 2013. O número representa $0,08 \%$ dos adolescentes dentre a população de 12 a 18 anos no país, conforme

\footnotetext{
${ }^{10}$ As informações foram concedidas durante entrevista com o juiz titular da Vara da Infância e da Juventude, Mauro Nering Karloh, realizada no dia 13 de dezembro de 2016, no gabinete do Fórum de Campo Grande.

${ }^{11}$ Dados retirados do "Levantamento anual: Sinase 2013", o estudo mais recente publicado pelo órgão até o período de captação dos dados para a presente pesquisa.
} 


\section{míDiA

comparativo feito pelo estudo com base na projeção da população feita pelo Instituto Brasileiro de Geografia e Estatística (IBGE), de 26.154.356 pessoas entre 12 e 18 anos. A pesquisa ainda apresenta a variação anual dos números de internação, internação provisória e semiliberdade no país. Em relação à série histórica, houve aumento de 10,5\% entre os anos de 2008 e 2010, já nos dois anos seguintes o índice cai 4,7\%, mas entre 2012 e 2013 volta a subir, com 12\% de aumento e superando a maior variação detectada.

Em Mato Grosso do Sul, no primeiro semestre do ano de 2015, total de 232 adolescentes cumpriam medida socioeducativa de internação ou semiliberdade por cometer alguma infração, de acordo com dados ${ }^{12}$ da Superintendência de Assistência Socioeducativa (SAS), que faz parte da Secretaria de Justiça e Segurança Pública do Estado (Sejusp-MS). A Superintendência é o órgão regional responsável por coordenar a implantação de políticas voltadas ao atendimento de adolescentes em conflito com a legislação, no âmbito das Unidades Educacionais de Internação (Uneis) ${ }^{13}$.

Em relação ao quantitativo de crimes, a SDH apresenta dados comparativos entre 2002, quando foram praticados 165 delitos por adolescentes em Mato Grosso do Sul; e 2010, quando o número subiu para 223 atos infracionais praticados. Entre os delitos, os de maior incidência em 2012 são: roubo (70), tráfico (44) e homicídio (37) (SDH, 2012). O roubo se mantém em primeiro lugar entre os delitos na última década e a mídia é apontada como um dos fatores contribuintes, de acordo com o relatório da Secretaria: “Tal motivação é alimentada pelas estratégias de marketing e propaganda do mercado, pelo apelo para o consumo e pela valorização social a partir da posse de bens materiais e com consequente empoderamento simbólico" (SDH, 2011, p. 23).

\section{Jornalismo on-line}

O jornalismo on-line é o campo de pesquisa deste trabalho, sendo os dois jornais analisados no formato digital. Palacios (2003) estabelece seis características do jornalismo desenvolvido para a web: multimidialidade/convergência, interatividade,

\footnotetext{
${ }^{12}$ Dados fornecidos via e-mail pela Superintendência de Assistência Socioeducativa (SAS), em 17 de fevereiro de 2017.

${ }^{13}$ Definição encontrada no endereço eletrônico da Sejusp-MS. Disponível em: http://www.sejusp.ms.gov.br. Acesso em: 14 mar. 2017.
} 


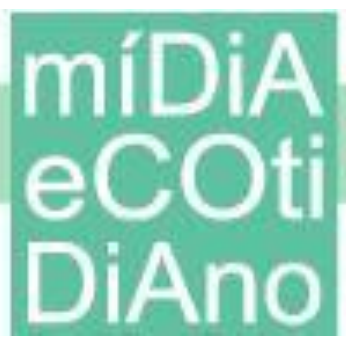

hipertextualidade, personalização, memória e instantaneidade do acesso, com a atualização contínua do material informativo. A essa lista, Canavilhas (2008) acrescenta uma sétima particularidade, a ubiquidade, que significa ser encontrado em todo lugar, e no contexto da mídia implica que "qualquer um, em qualquer lugar, tem acesso potencial a uma rede de comunicação interativa em tempo real" (PAVLIK, 2014). É importante esclarecer que nem todos os meios on-line precisam necessariamente ter todas as características - e muitos ainda não as têm ou estão em fase de aperfeiçoamento (PALACIOS, 2003).

A instantaneidade do acesso é a característica com maior impacto no tema pesquisado, já que a rapidez na divulgação de informações pode refletir em dados equivocados sobre o adolescente e a infração cometida, além de transgressões ao Estatuto da Criança e do Adolescente. Sodré (2009) destaca que a busca pela atualidade, informação em tempo real, passou a ter até mais valor que o próprio conteúdo. A velocidade é imposta ao jornalismo on-line, fazendo do trabalho nas redações uma “corrida contra o tempo" para alimentar o sistema (MORETZSOHN, 2002, p. 130). Do outro lado, o público também cobra atualizações em tempo real, sendo que o jornal online que fugir desse padrão corre o risco de ser considerado ocioso. Pavlik (2001, p. 21) afirma que as pessoas querem e buscam suas notícias em tempo real.

A rapidez do acesso, combinada com a facilidade de produção e de disponibilização, propiciadas pela digitalização da informação e pelas tecnologias telemáticas, permitem uma extrema agilidade de atualização do material nos jornais da web. Isso possibilita o acompanhamento contínuo em torno do desenvolvimento dos assuntos jornalísticos de maior interesse (PALACIOS, 2003, p. 4).

Essa corrida pelo imediatismo, no entanto, também trouxe prejuízos para o material divulgado, que muitas vezes, em nome da instantaneidade, perde qualidade por conta da falta de tempo hábil para a devida edição e apuração. Moretzsohn (2002) afirma que "a velocidade é consumida como fetiche, pois 'chegar na frente' torna-se mais importante do que 'dizer a verdade': a estrutura industrial da empresa jornalística está montada para atender a essa lógica” (MORETZSOHN, 2002, p. 120).

Bernardo Kucinski (2005) também critica o fascínio pela instantaneidade por prejudicar atributos fundamentais da informação, como precisão, contextualização e 


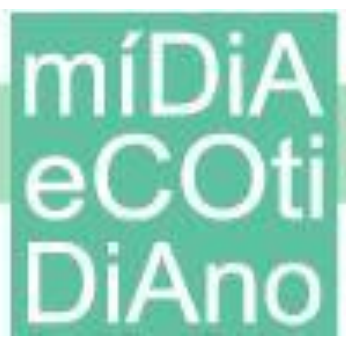

interpretação. A cobrança pela agilidade, acredita Moretzsohn (2002, p. 63), é o grande motivador de erros nas informações. Isso porque muitas vezes o jornalista precisa publicar a notícia sem antes ter tido tempo hábil para checar devidamente as informações do entrevistado ou procurar outras fontes para comprovar os dados. Há ainda a incidência de erros de ortografia e concordância por falta de revisão. Esse tipo de equívoco ganha proporções maiores quando se trata do espaço virtual, pois a velocidade com que a informação é compartilhada é muito maior do que em outros meios e, mesmo após a correção, o erro pode permanecer circulando na rede porque algum receptor salvou o conteúdo inicial e compartilhou.

\section{Mapeamento metodológico}

A metodologia aplicada será a análise de conteúdo, adaptada conforme a proposta do trabalho, por permitir utilizar dados quantitativos e qualitativos, além de ser um método que se ocupa basicamente da análise de mensagens. Fonseca Jr. (2011, p. 286) explica que essa metodologia permite ao pesquisador programar, comunicar e avaliar criticamente uma pesquisa com independência de resultados. O método é eficiente para ser aplicado em grande volume de informações, como será o caso desta pesquisa, com 206 matérias coletadas. Para os estudos de jornalismo, a análise de conteúdo ainda tem grande eficácia por ajudar na verificação de frequência de pessoas - neste caso, o adolescente - além de situações e acontecimentos que aparecem na mídia por meio de categorias definidas (HERSCOVITZ, 2007).

Os veículos de comunicação para exploração dos dados foram definidos a partir dos seguintes critérios: tempo de criação (como fator determinante) e conteúdo exclusivamente digital. Campo Grande News e Midiamax foram os dois portais de notícias selecionados para o levantamento. O mês de recorte foi junho de 2016, determinado por ser estratégico dentro do cronograma de execução da presente pesquisa e um intervalo sem férias escolares, recesso ou feriado nacional - apenas o feriado municipal, no dia 13, devido à comemoração do padroeiro da Capital, Santo Antônio.

Para a coleta, os sites foram observados diariamente durante o mês de junho de 2016. As matérias foram selecionadas por meio da ferramenta de busca interna, que tanto o Midiamax como o Campo Grande News oferecem. Foi utilizada a palavra-chave 


\section{miDiA

"adolescente", no singular e plural, como filtro para capturar apenas as notícias com a temática de interesse para a pesquisa. Após coletar todas as matérias publicadas ao longo do mês que continham a palavra "adolescente", o conteúdo passou por análise prévia. Decidiu-se por desconsiderar para o estudo final todas as notícias com: conteúdo nacional ou internacional, republicado a partir de agências ou jornais nacionais; artigos e informes publicitários. O descarte considerou que o alvo da presente pesquisa é a investigação do conteúdo jornalístico on-line regional produzido pelos dois jornais. No Campo Grande News, as notícias da editoria "Lado B" também foram retiradas por tratar-se de conteúdo de entretenimento.

A exploração dos dados foi realizada a partir de categorizações para classificar e conduzir as análises. O trabalho final resultou em três categorias, sendo que neste artigo serão apresentados os resultados de apenas uma, que concentra as matérias sobre adolescente em conflito com a lei, com objetivo de responder à pergunta: quais são os tipos de infrações em que esses indivíduos mais aparecem envolvidos no noticiário? A averiguação dos dados ainda irá identificar se as matérias que tratam sobre o adolescente em conflito com a lei utilizam imagens e se essas respeitam às diretrizes do ECA em relação à preservação da identidade da pessoa com menos de 18 anos.

\section{Análise de dados e resultados}

Dentre os 30 dias observados, foram encontradas 78 notícias sobre adolescentes em conflito com a lei, ou seja, uma média de 2,5 publicações por dia sobre o assunto nos dois sites de Campo Grande. O volume representou a maior parcela do total de dados coletados, correspondendo a 37,8\% das 206 notícias que tinham no texto a palavra adolescente. O Campo Grande News tem a maior incidência desse tipo de conteúdo, com 38 matérias, o que representou 40,86\% do montante de informações, enquanto o Midiamax apresentou 40 itens, correspondendo a 35,39\%.

As análises têm como alvo averiguar os crimes mais noticiados e a utilização de imagens, identificando se há inclinação para publicações mais violentas e o respeito às diretrizes do ECA. O resultado mostrou que o homicídio foi o delito mais publicado, com 25 matérias nos dois jornais, seguido pelo roubo, com 20. Em seguida está o tráfico ou porte de drogas, com 10, e outros somaram 17 notícias. O Gráfico 1 mostra que no Campo Grande 
News a maior incidência é de publicações em que o adolescente aparece como autoria do crime de homicídio (15), seguido pelo roubo (6), tráfico ou porte de drogas (4) e furto (3). Já no Midiamax, conforme mostra o Gráfico 2, o roubo está em primeiro lugar, com 14 publicações em que o adolescente é autor, suspeito ou cúmplice. O homicídio vem em seguida com 10 casos; o tráfico ou porte de drogas para uso tem 6 notícias; e furto com três.

\section{Gráfico 1 - Atos infracionais praticados por adolescentes noticiados pelo Campo Grande} News

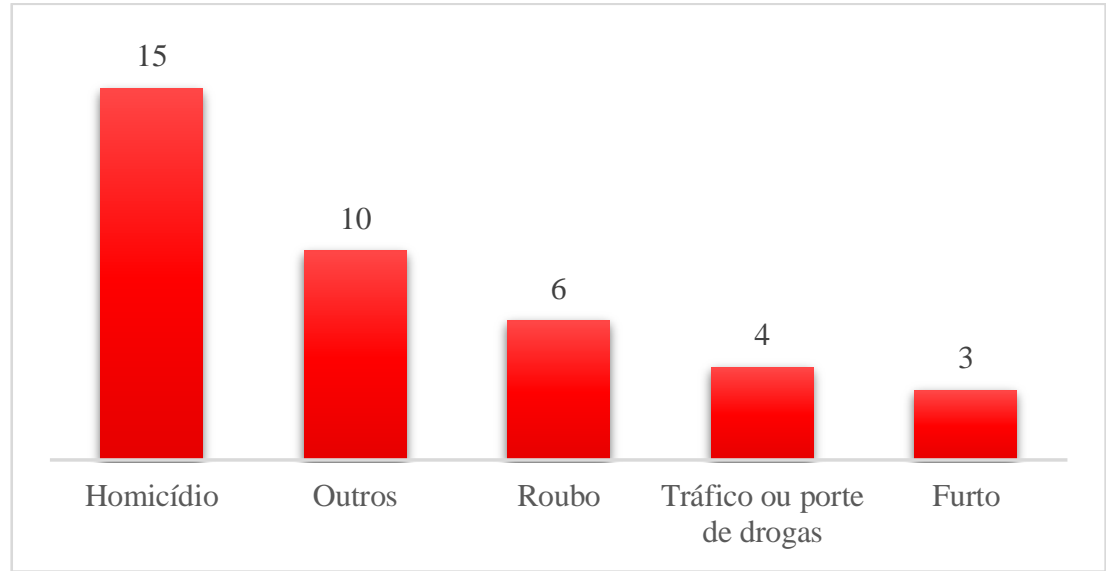

Fonte: Elaborado pelas autoras.

\section{Gráfico 2 - Atos infracionais praticados por adolescentes noticiados pelo Midiamax}

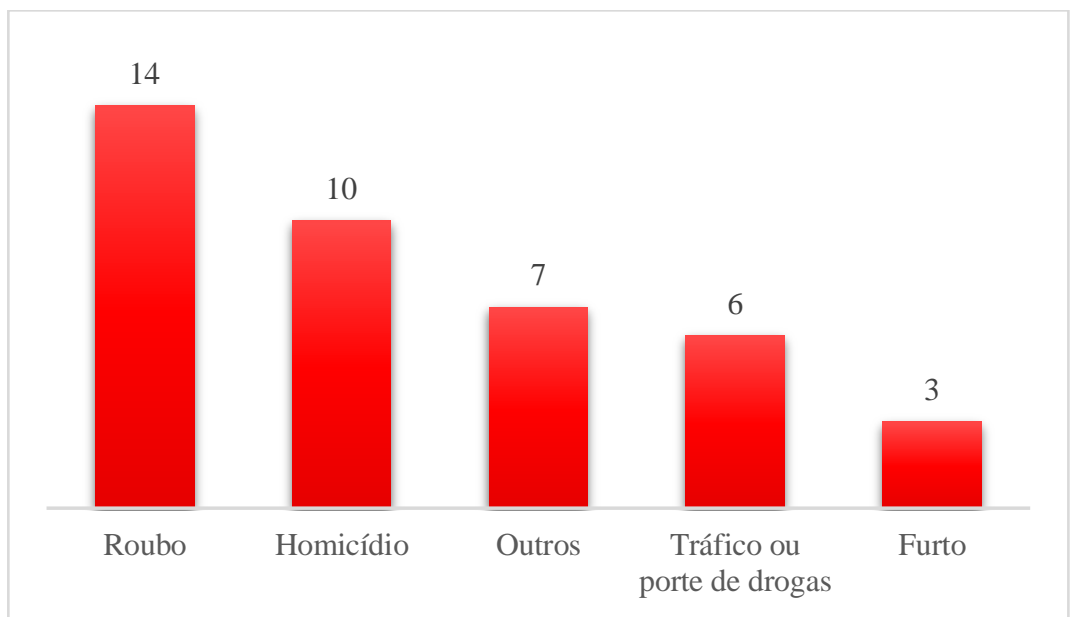

Fonte: Elaborado pelas autoras.

Das 38 publicações reunidas no Campo Grande News, 27 tem a utilização de imagens, já no Midiamax a fotografia aparece em apenas 10 das 40 matérias coletadas. A 
presença de fotos, portanto, corresponde a $71 \%$ do material do CGNews e $25 \%$ do Midiamax, o que indica uma característica editorial do primeiro jornal por optar com mais frequência pelo uso de imagens para ilustrar as informações. Entre as imagens do CGNews, parcela de $11 \%$ (ou seja, três matérias) tem evidências de desrespeito ao ECA. Apesar da parcela menor de notícias com fotos no Midiamax, a fatia de imagens em desacordo com o ECA é semelhante em números absolutos, com duas matérias, e superior quando mensurado o percentual, de $20 \%$ do total de 10 publicações ilustradas. Nos dois sites, o restante das matérias conta com fotos das vítimas, objetos apreendidos ou cenários policiais, seja a fachada de delegacia ou dos próprios policiais e delegados atuantes nos casos relatados.

Apesar de ser minoria, as matérias com imagens inadequadas revelam a exposição irregular feita pela mídia em relação aos adolescentes que cometem infrações. Na notícia 1 do Campo Grande News: "Três jovens são presos e um adolescente apreendido em desmanche de motos", do dia 1 de junho de 2016, a fotografia é da fachada da casa onde o flagrante do crime foi feito pela Polícia, conforme mostra a Figura 1 abaixo. $\mathrm{O}$ texto não deixa claro se o adolescente apreendido também morava no local, o que caracterizaria exposição do endereço e, consequentemente, de sua identidade.

Figura 1 - Imagem referente à notícia "Três jovens são presos e um adolescente apreendido em desmanche de motos", do dia 1 de junho de 2016 do site Campo Grande News

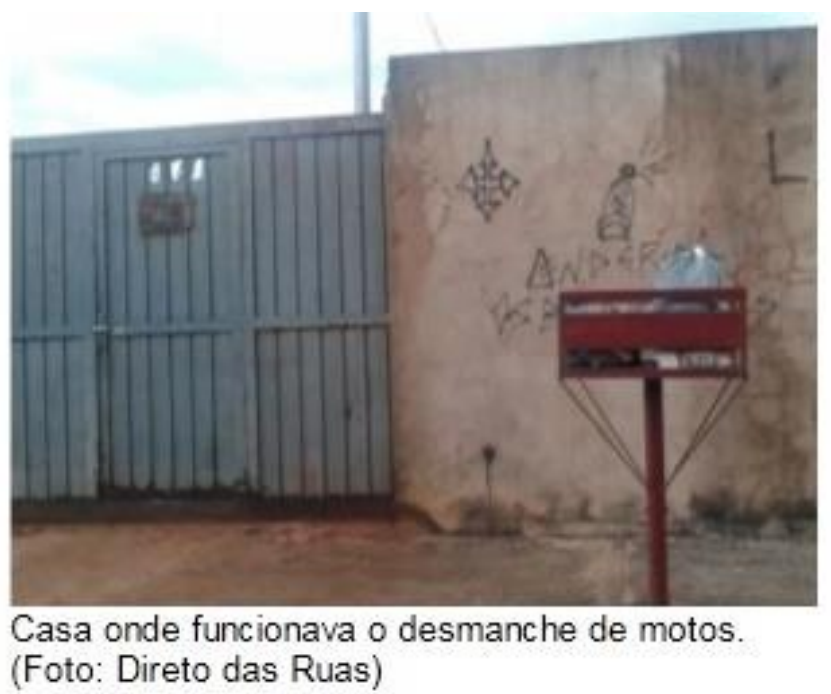

Fonte: https://www.campograndenews.com.br/. Acesso em: 2 jun. 2016. 
Em "Adolescentes, um deles de 14 anos (evidencia a idade), são apreendidos após assalto", publicada no dia 3 de junho de 2016, os adolescentes aparecem ajoelhados, de costas, em local que aparenta ser uma delegacia, como mostra a Figura 2. A foto, mesmo sem mostrar o rosto, permite a identificação dos autores por conhecidos, além de submeter os adolescentes a exposição constrangedora. Situação semelhante é a do terceiro caso, "Adolescente que participou de assalto com confronto e morte é apreendido", do dia 20 de junho de 2016, em que a fotografia mostra o adolescente autor do assalto, de costas, junto a motocicletas, de acordo com a Figura 3.

Figura 2 - Imagem referente à notícia 2 "Adolescentes, um deles de 14 anos, são apreendidos após assalto", publicada no dia 3 de junho de 2016 do site Campo Grande News

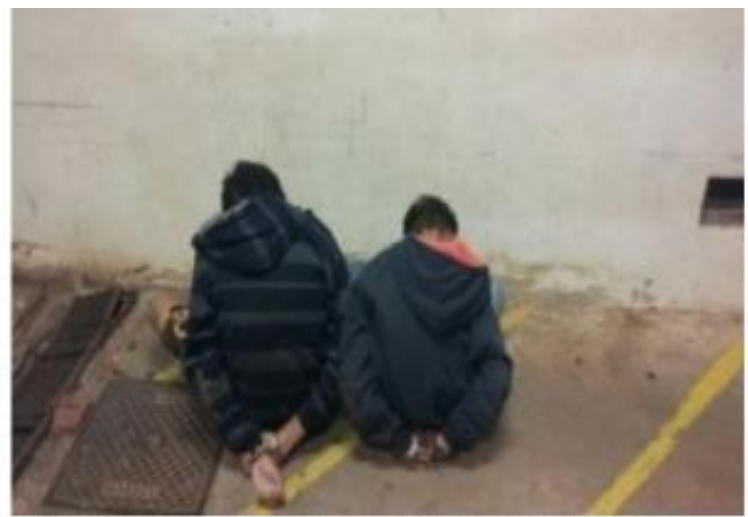

Os dois adolescentes foram apreendidos e levados à delegacia. (Foto: divulgação/Guarda Municipal)

Fonte: https://www.campograndenews.com.br/. Acesso em: 4 jun. 2016. 


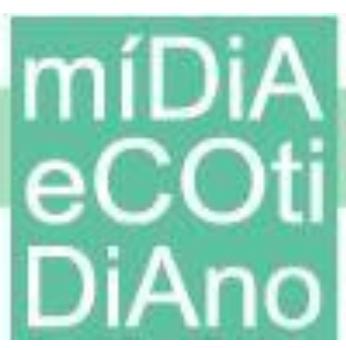

\section{PPGMC}

vff

Figura 3 - Imagem referente à notícia "Adolescente que participou de assalto com confronto e morte é apreendido", do dia 20 de junho de 2016 do site Campo Grande News

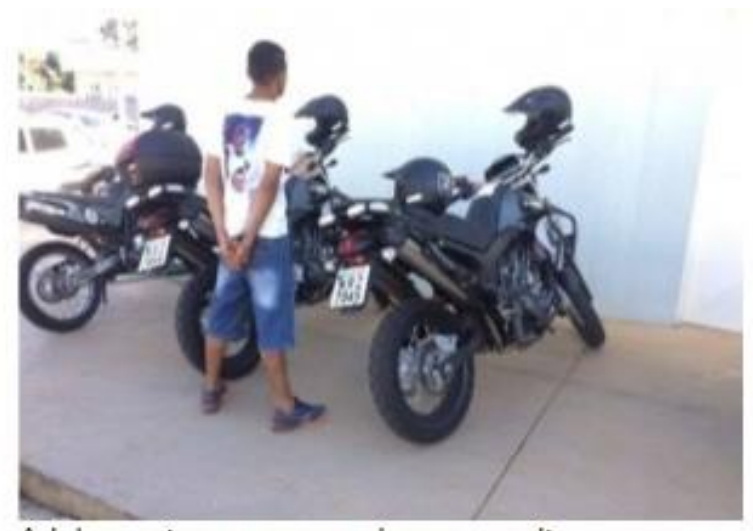

Adolescente era procurado por assalto em que o comparsa acabou morto pela PM, após perseguição (Foto:Divulgação/PMMS)

Fonte: https://www.campograndenews.com.br/. Acesso em: 22 jun. 2016.

No Midiamax, a matéria 1: "PM flagra 19 adolescentes e apreende drogas em boate de MS", do dia 12 de junho de 2016, mostra na imagem o momento da abordagem dos policiais, com os adolescentes ao fundo e as mãos na parede, conforme a Figura 4. O registro dos adolescentes está em segundo plano, mas ainda assim os expõe.

Figura 4 - Imagem referente à notícia "PM flagra 19 adolescentes e apreende drogas em boate de MS", do dia 12 de junho de 2016 do site Midiamax

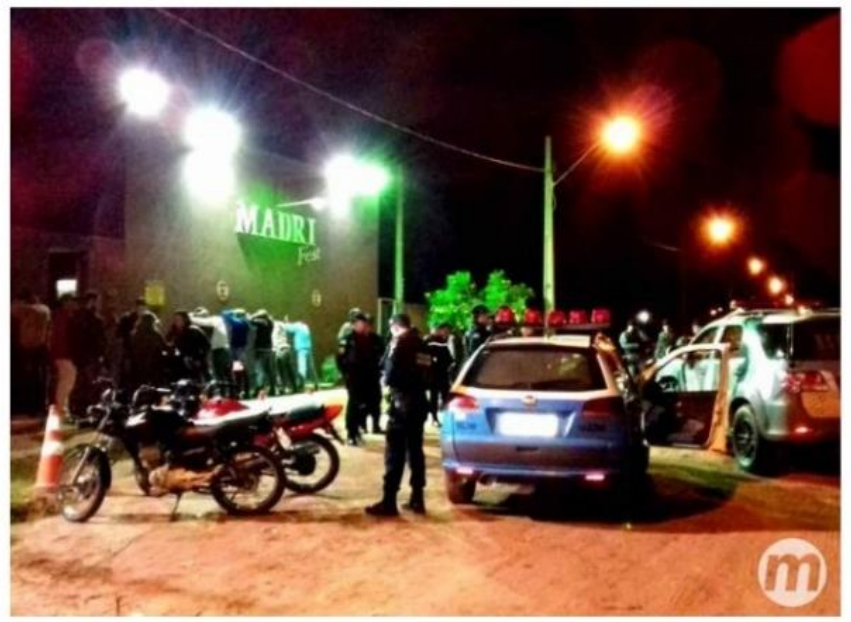

- No local, foram encontrados ainda quatro trouxinhas com substância análoga a cocaina, lançados ao solo, e dentro do banheiro feminino pequenas porções de substância análoga a maconha (Divulgação PM)

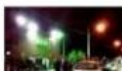

Fonte: https://www.midiamax.com.br/. Acesso em: 13 jun. 2016. 


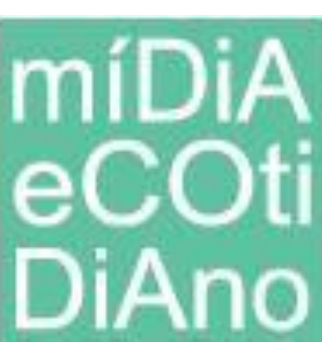

\section{PPGMC}

No dia 30 de junho de 2016, a notícia 2: “Adolescente matou mulher em escadaria com mais de 40 facadas" mostra a foto da adolescente autora do homicídio, cortando o rosto para não revelar a identidade, no entanto, são reveladas características físicas, como as tatuagens no braço e mão, que permitem a identificação, como mostra Figura 5.

Figura 5 - "Adolescente matou mulher em escadaria com mais de 40 facadas" 30 de junho de 2016 do site Midiamax

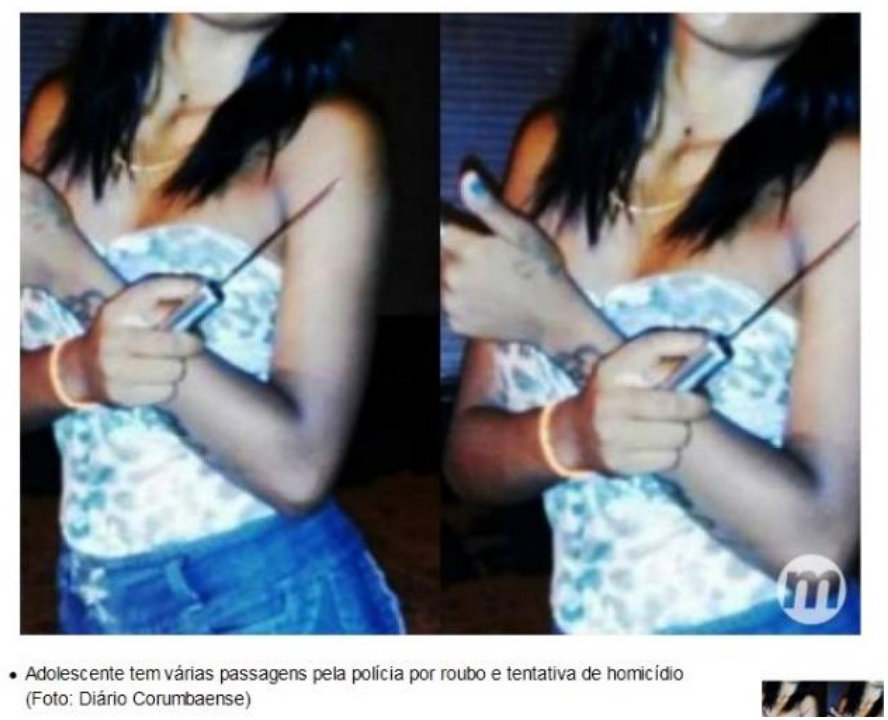

Fonte: https://www.midiamax.com.br/. Acesso em: 1 jul. 2016.

No geral, das 78 matérias, 37 utilizavam imagens para ilustrar o texto, sendo que em 13,5\% dessas (cinco notícias) foram identificados elementos nas fotografias que permitiam a identificação do adolescente, contrariando as diretrizes do ECA em relação à preservação da identidade da pessoa com menos de 18 anos. $\mathrm{O}$ resultado segue a tendência apresentada em levantamento com 54 jornais impressos do país feito pela ANDI (2012a), no qual foram analisadas 2.236 notícias que tratavam do adolescente em conflito com a lei. Dentre o material coletado, $12 \%$ apresentavam fotos que desrespeitavam o que preconiza o Estatuto. 


\section{míDiA

\section{Considerações finais}

A frequente divulgação do adolescente relacionado ao tema violência pode levar a sociedade a associar, primordialmente, esse indivíduo às práticas violentas, quando na verdade os assuntos que dizem respeito a ele abrangem diversas outras áreas. Os direitos garantidos em legislação específica, como educação e saúde, são deixados em segundo plano quando o principal interesse é distribuir informações apenas negativas. Essa questão é enfatizada em documento da Organização das Nações Unidas para a Educação, a Ciência e a Cultura (UNESCO, 2004) ao afirmar que a maioria da imprensa mostra o jovem como um problema, sendo raras as vezes em que se divulgam iniciativas positivas desses por considerarem que tais assuntos não atraem o público.

Compreende-se que a seleção de notícias pode ser crucial para determinado assunto ser discutido na sociedade, já que o jornalista, mesmo que indiretamente, influencia a maneira como o tema será tratado pelas pessoas e, ainda, se será amplamente discutido. "Os media definem para a maioria da população quais os acontecimentos significativos que ocorrem, mas também, oferecem poderosas interpretações de como compreender esses acontecimentos" (HALL apud TRAQUINA, 2005, p. 177).

Os resultados destacam o desrespeito ou até mesmo o desconhecimento por parte do jornalista e dos meios de comunicação on-line sobre a legislação que diz respeito ao adolescente e o consequente despreparo para lidar com o tema durante a cobertura diária.

Os resultados desta pesquisa devem alertar aos jornalistas sobre a frequência do assunto na pauta, os desrespeitos em relação à legislação e oferecer dados para o aprimoramento da cobertura, possibilitando evitar ou pelo menos amenizar os impactos negativos de informações distorcidas sobre este tópico de relevância para a sociedade.

\section{Referências}

ACIOLI, Márcia Hora. Entrevista especial: 22 anos do ECA. INESC - Instituto de Estudos Socioeconômicos, 2012. Disponível em: https://fc.tmp.br/inesc/en/entrevista-especial-22-anosdo-eca-2/. Acesso em: 22 fev. 2017.

ANDI - Comunicação e Direitos. Como os jornais brasileiros abordam as temáticas relacionadas ao adolescente em conflito com a lei?: Uma análise da cobertura de 54 diários entre 2006 e 2010. Direitos em Pauta: imprensa, agenda social e adolescentes em conflito com a lei. Brasília, 2012a. 
Adolescentes em conflito com a lei: Guia de referência para coberturas jornalísticas. Brasília, 2012b. Disponível em: http://www.andi.org.br. Acesso em: 15 maio 2015.

BERTRAND, Claude-Jean. A deontologia das mídias. São Paulo: EDUSC, 1999.

BRASIL. Lei no 8069, de 13 de junho de 1990. Dispõe sobre o Estatuto da Criança e do Adolescente e dá outras providências. Lex: Vade Mecum. 9. ed. São Paulo: Saraiva, 2010. p. 1445 .

CANAVILHAS, João. Cinco Ws e um H para o jornalismo na web. Prisma.com, Porto, n. 7, p. 153-172, 2008. Disponível em: http://ojs.letras.up.pt/index.php/prismacom/article/view/2076.

Acesso em: 14 jan. 2017.

FENAJ - FEDERAÇÃO NACIONAL DOS JORNALISTAS. Código de Ética dos Jornalistas Brasileiros. 2007. Disponível em: https://fenaj.org.br/wp-content/uploads/2014/06/04codigo_de_etica_dos_jornalistas_brasileiros.pdf. Acesso em: 24 ago. 2016.

FONSECA JUNIOR, Wilson Corrêa da. Análise de Conteúdo. In: DUARTE, Jorge; BARROS Antonio. Métodos e técnicas de pesquisa em comunicação. 2. ed. São Paulo: Atlas, 2011.

GALTUNG, Johan; RUGE, Mari Holmboe. The structure of foreign news: The presentation of the Congo, Cuba and Cyprus crises in four Norwegian newspapers. Journal of peace research, v. 2, n. 1, p. 64-90, 1965.

GUIMARÃES, Paula Vitorino. O adolescente infrator em pauta: a presença de matérias sobre delitos envolvendo adolescentes na pauta diária do jornal on-line Campo Grande News. Revista Comunicação e Mercado/Unigran, Dourados, v. 04, n. 10, p. 118-129, jul-dez, 2015.

HERSCOVITZ, Heloisa Golspan. Análise de conteúdo em jornalismo. In: LAGO, Cláudia; BENETTI, Márcia. (Eds.). Metodologia de Pesquisa em Jornalismo. Rio de Janeiro: Vozes, 2007. p. 123-142.

KARLOH, Mauro Nering. Entrevista pessoal. 6 dez. 2016.

KUCINSKI, Bernardo. Jornalismo na era virtual: ensaios sobre o colapso da razão ética. São Paulo: Fundação Perseu Abramo/UNESP, 2005.

MORETZSOHN, Sylvia. Jornalismo em "tempo real": o fetiche da velocidade. Rio de Janeiro: Revan, 2002.

PALACIOS, Marcos. Ruptura, Continuidade e Potencialização no Jornalismo Online: o lugar da memória. In: MACHADO, Elias; PALACIOS, Marcos. (Orgs). Modelos do Jornalismo Digital. Salvador: Calandra, 2003.

PAVLIK, John V. Journalism and new media. New York, Columbia: 2001. Ubiquidade: o $7 .^{\circ}$ princípio do jornalismo na era digital. In: CANAVILHAS, João (Org.). Webjornalismo: 7 caraterísticas que marcam a diferença. Covilhã: LabCom, 2014.

ROTHBERG, Danilo; BERTI, Pedro Luis Bueno. Políticas públicas e direitos de crianças e adolescentes: o papel da mídia na expansão da cidadania. Estudos em Jornalismo e Mídia, v. 7, n. 2, p. 237-248, 2010. 
SECRETARIA DOS DIREITOS HUMANOS. Levantamento nacional: Atendimento Socioeducativo ao Adolescente em Conflito com a Lei. Brasília: SDH, 2012.

. Levantamento anual: Sinase 2013. Brasília: SDH, 2015.

SILVA, Edson. La construcción social de la realidad de niños y adolescentes en la prensa de Campo Grande, Mato Grosso do Sul-Brasil. 2013. 719 f. Tese (Doutorado em Comunicación y Periodismo) - Universidad Autónoma de Barcelona, Espanha, 2013.

SILVA, Gislene. Para pensar critérios de noticiabilidade. In: SILVA, Gislene; SILVA, Marcos Paulo; FERNANDES, Mário Luiz (Orgs.). Critérios de noticiabilidade: problemas conceituais e aplicações. Florianópolis: Insular, 2014.

SILVA, Marcos Paulo. Perspectivas históricas da análise da noticiabilidade. In: SILVA, Gislene; SILVA, Marcos Paulo; FERNANDES, Mário Luiz. (Orgs.). Critérios de noticiabilidade: problemas conceituais e aplicações. Florianópolis: Insular, 2014.

SODRÉ, Muniz. A narração do fato: notas para uma teoria do acontecimento. Petrópolis, RJ: Vozes, 2009.

TRAQUINA, Nelson. Teorias do Jornalismo: porque as notícias são como são. 2. ed. Florianópolis: Insular, 2005. $1 \mathrm{v}$.

UNESCO. Políticas públicas de/para/com as juventudes. Brasília: UNESCO, 2004. 